\title{
APROXIMAÇÕES ENTRE AVALIAÇÃO E CURRÍCULO NA EDUCAÇÃO DE JOVENS, ADULTOS E IDOSOS
}

\author{
APROXIMATIONS BETWEEN EVALUATION AND CURRICULUM IN EDUCATION OF YOUTH, ADULTS AND ELDERLY
}

APROXIMACIONES ENTRE EVALUACIÓN Y CURRÍCULO EN LA EDUCACIÓN DE JÓVENES, ADULTOS Y IDOSOS

\author{
LOPES, Reijane da Silva 1 \\ VIEIRA, Maria Clarisse ${ }^{2}$
}

\section{RESUMO}

Os sujeitos da Educação de Jovens e Adultos (EJA) demandam um currículo e práticas avaliativas diferenciadas. Em consonância com esta ideia, este artigo tem como objetivo analisar as aproximações entre o processo avaliativo e o currículo prescrito e vivido na primeira etapa da EJA de uma escola pública do Distrito Federal e sua pertinência com os documentos vigentes na Secretaria de Estado de Educação do DF - SEEDF. A pesquisa constituiu-se em observações e intervenções em sala de aula, dentro de uma perspectiva de pesquisa-ação. O estudo desvelou aproximações e distanciamentos entre o currículo prescrito e o vivido, reflexões importantes para todos os que lidam com esta modalidade.

Palavras-chave: Currículo. Processo avaliativo. EJA. Avaliação formativa.

\section{ABSTRACT}

Youth and Adult Education require a curriculum and differentiated evaluation practices. In line with this idea, this article aims to analyze the approximations between the evaluation process and the curriculum prescribed and lived in the first stage of this area, in a public school in Distrito Federal and its relevance to the current documents at the State Department of Education of the Distrito Federal - SEEDF. The research consisted on the observations and interventions in the classroom, within an actionresearch perspective. The study revealed approximations and distances between the prescribed curriculum and the lived one, which brings important reflections for all that deal with this modality.

Keywords: Curriculum. Evaluation process. EJA. Formative evaluation.

\section{RESUMEN}

Los sujetos de Educación de Jóvenes y Adultos (EJA) demandan un currículo y prácticas evaluativas diferenciadas. En consonancia con esta idea este artículo tiene como objetivo analizar las aproximaciones entre el proceso evaluativo y el currículo prescrito y vivido en la primera etapa de la EJA de una escuela pública del Distrito Federal y su pertinencia con los documentos vigentes en la Secretaría de Estado de Educación del Estado, DF - SEEDF. La investigación se constituyó en observaciones e intervenciones en el aula, dentro de una perspectiva de investigación-acción. El estudio desveló aproximaciones y distanciamientos entre el currículo prescrito y el vivido, reflexiones importantes para todos los que se ocupan de esta modalidad.

Palabras clave: Currículo. Proceso de evaluación. EJA. Evaluación formativa.

\footnotetext{
1 Universidade de Brasília -UnB - Brasília - Brasil

2 Universidade de Brasília -UnB - Brasília - Brasil
} 


\section{INTRODUÇÃO}

A Educação de Jovens e Adultos (EJA) é uma modalidade educativa voltada a classe trabalhadora de jovens, adultos e idosos que não iniciaram a escolarização na idade apropriada ou que a interromperam em função de situações adversas. Dessa maneira, as idiossincrasias desses sujeitos ${ }^{3}$ demandam um currículo e práticas avaliativas diferenciadas, que valorizem a sua história de vida e seus saberes. Para tanto, é mister situá-los/as em seu contexto histórico-cultural de um viver incerto, ocasionado pelo trabalho informal que, muitas vezes, os força a sobreviver em uma sociedade que os mantém alijados/as de seus direitos.

A EJA é uma dívida histórica do Estado para com os/as educandos/as trabalhadores/as que, por não pertencerem à faixa etária de oferta obrigatória, estiveram, por muito tempo, à margem do sistema educacional. Além disso, a EJA sempre foi relegada às políticas de governo, que se concretizaram em função da articulação da sociedade civil, por meio dos movimentos populares, que ganharam destaque em 196 e se opunham a desobrigação do Estado para com esse público. Com Paulo Freire, disseminou-se um movimento de educação popular. Um tipo de educação voltada para os excluídos do campo e da cidade, com o propósito de resgatar a "cultura pensada e vivida pelo povo" (BRANDÃO, 2008, p. 28), numa dimensão política e pedagógica, em prol de uma escola para todos, que respeita os ritmos individuais e valoriza os percursos formativos dos/as educandos/as, numa perspectiva libertadora de aprendizagem.

Uma pedagogia para os/as oprimidos/as, para além da opressão, capaz de superar as desigualdades sociais presentes dentro e fora das escolas; que os reconheça como sujeitos, protagonistas de suas próprias histórias. Para Vieira (2016), faz-se necessário entender as "outras" histórias da EJA, para que se tenha uma concepção de história diferente da hegemônica, desvelando, assim, saberes e práticas mais humanas e emancipatórias. Um cenário ideal, mas difícil de se consubstanciar, pois o sistema educacional vigente possui uma estrutura política e curricular que dificulta a implementação de tais práticas.

Considerando esta realidade, é necessário que durante a seleção de conteúdos, metodologia e avaliação, haja uma clareza dos aspectos sociais, políticos e pedagógicos que envolvem o ato educativo. Ou seja, ao reconhecer a EJA como uma modalidade voltada para pessoas da classe trabalhadora, é mister que seu currículo dialogue com as singularidades e incorpore as especificidades e diversidades presentes no universo dos seus sujeitos, considerando, de forma integrada, suas origens, culturas, saberes, conhecimentos e projetos de vida.

Este artigo traz resultados de pesquisa mais ampla, cujo lócus é uma Escola localizada no Paranoá - Distrito Federal. Espaço no qual o Grupo de Ensino-Pesquisa-Extensão em Educação Popular e Estudos Filosóficos e Histórico-Culturais (GENPEX) acompanha desde 2015 os/as egressos/as da alfabetização, oriundos/as do Programa DF Alfabetizado, por meio de projeto de inclusão digital para os/as alfabetizandos/as do primeiro segmento do Ensino Fundamental da

\footnotetext{
${ }^{3}$ Sempre que estiver me referindo aos estudantes da EJA, acrescentarei o artigo "a" ou "as", a fim de reforçar questões de identidade de gênero que costumam ser relegadas.
} 
Educação de Jovens e Adultos. O DF Alfabetizado é a versão "candanga" do Programa Brasil Alfabetizado, criado em 2003 pelo MEC em parceria com movimentos populares, cujo trabalho consiste, entre outros encargos, na alfabetização de jovens, adultos/as e idosos/as, possibilitando, posteriormente, a continuidade da escolarização na rede pública de ensino.

O GENPEX tem como matriz epistemológica a perspectiva histórico-cultural e a metodologia da pesquisa-ação, referendada em René Barbier (2002) e Michel Thiollent (1997). De acordo com Thiollent (1997), a pesquisa-ação é um tipo de pesquisa social com base empírica, concebida e realizada em estreita associação com uma ação

[...] ou com uma resolução de um problema coletivo, e no qual os pesquisadores e os participantes representativos da situação ou problema estão envolvidos de modo cooperativo ou participativo. (Thiollent, 1997, p. 14).

A pesquisa-ação não é constituída apenas pelo caráter participativo, mas inclui uma dimensão de produção de conhecimento, que pode ser útil não apenas para a coletividade considerada na investigação, mas para um público mais amplo.

É importante mencionar que este grupo, criado em 2000, tem suas origens relacionadas ao movimento de ocupação da Região Administrativa do Paranoá, em Brasília. Iniciado com a construção da capital federal, quando brasileiros oriundos de diversas regiões do País, migraram para essa região e iniciaram um processo de luta pela moradia e fixação no território. A luta em prol da posse definitiva da terra estrutura-se e torna-se sistematizada a partir dos anos 1970 e 1980, por meio da mobilização de um grupo de jovens, ligados à igreja católica, que iniciam um trabalho político pastoral de conscientização da comunidade. Estes jovens se organizam em uma associação de moradores e passam a pressionar, de forma mais efetiva, o poder público pela fixação da população e o fornecimento de serviços básicos, como educação, saúde, água, luz, esgoto, segurança e transporte.

É nesse contexto, que percebem a educação de adultos como forma de fortalecer a luta e fixação da população na cidade, visto que a maioria dos moradores não era alfabetizada. Inicialmente, procurou-se apoio da igreja católica local, mas para que o trabalho se expandisse, necessitavam de apoio pedagógico. Como, naquele momento, esse apoio era negado pelo Estado, foram buscá-lo, em 1986, na Faculdade de Educação da Universidade de Brasília - UnB. Desde então, a UnB desenvolve, em parceria com o Movimento Popular (Centro de Desenvolvimento e Cultura do Paranoá - CEDEP), trabalho educativo voltado à educação e formação de educadores de jovens e adultos/as na região administrativa do Paranoá/ltapoã.

Importante mencionar que até 2015 , a práxis do Genpex estava restrita aos espaços do Movimento Popular. No entanto, a partir deste período, este desafio se estendeu a rede pública de ensino. Este processo de ampliação tem origem em 2011, com o lançamento do Programa DF Alfabetizado, que tem como base a Resolução CD/FNDE n 32 (BRASIL, 2011), fruto da adesão, ainda que tardia, do Governo do Distrito Federal ao Programa Brasil Alfabetizado (PBA), lançado em 2003. A referida parceria, materializou-se na atuação conjunta do CEDEP, GENPEX e Coordenação Regional de Ensino, visando à formação dos alfabetizadores do Paranoá e Itapoã e a criação de turmas de 
alfabetização na região. Foram viabilizadas quatro edições do DF Alfabetizado, realizadas em 2012, 2013, 2014 e 2016. Estima-se que até 2014, houve o atendimento de quase 1000 educandos, em 52 turmas, com média de 15 educandos/as. Em 2015, por problemas operacionais relativos ao repasse de recursos para pagamento da bolsa aos alfabetizadores e transição governamental, não foi possível a realização do Programa.

Neste momento, o movimento popular questionou-se acerca da continuidade dos/as estudantes egressos/as do Programa DF Alfabetizado, na rede pública, na EJA. Onde estariam os/as estudantes egressos/as? Como estimular e contribuir no acesso e permanência destes estudantes no contexto da EJA? Buscando responder a esse desafio, em 2015, iniciou-se uma articulação com integrantes da coordenação intermediária de EJA da Regional de Ensino para encontrar um espaço possível para esse acompanhamento na Rede Pública de Ensino. Desde então, este trabalho tem ocorrido no laboratório de informática desta Escola do Paranoá, com todas as turmas do primeiro segmento da Educação de Jovens e Adultos. Esse fazer pedagógico tem como desafio integrar a informática, as linguagens de português e matemática e as situações-problema-desafios vividas pelos/as educandos/as da EJA, moradores/as do Paranoá e Itapoã. Para isso, as perspectivas da educação popular, aliado aos princípios da educação libertadora e à abordagem histórico-cultural, constituem-se como referência.

Este artigo apresenta resultados de investigação desenvolvida no interior desta instituição, cujo objetivo foi analisar as aproximações entre o processo avaliativo e o currículo prescrito e vivido na primeira etapa do primeiro segmento da EJA. Trata-se de estudo de caráter exploratório, inserido em uma perspectiva de pesquisa-ação. Os dados foram produzidos por meios da observação participante, nas aulas de Matemática e Português, e da aplicação de questionário para obtenção de informações sobre o perfil dos/as educandos/as. Também se utiliza anotações do Diário de Itinerância e análise do Projeto Político Pedagógico (PPP) da escola e dos documentos da Secretaria de Estado de Educação do DF (SEEDF), referentes à modalidade. Por intermédio da triangulação dos dados, buscou-se desvelar as aproximações e distanciamentos entre a prática pedagógica e o processo avaliativo vividos na Escola pesquisada.

\section{PORQUE É IMPORTANTE UM CURRÍCULO E UMA AVALIAÇÃO DIFERENCIADOS NA EJA}

$\mathrm{Na}$ concepção de Arroyo (2017), os/as educandos/as da EJA são sujeitos que vêm de itinerários humanos-desumanos, expulsos/as de sua terra pelo desemprego e pela fome; segregados/as, vitimados/as, marginalizados/as - política, econômica, social e pedagogicamente; oriundos/as de famílias pobres - trabalhadoras, negras e camponesas; marcados/as pelo trabalho infantil e pelo viver provisório - sem prazo, em espaços pobres, distantes e marginais; que sobrevivem do trabalho informal; e constituem identidades coletivas - de classe, raça e gênero.

A fim de compreender como se consubstancia essas especificidades na primeira etapa da Escola pesquisada, foi utilizado questionário para obtenção de dados sobre os/as educandos/as, o qual 
foi aplicado individualmente, em uma das salas de aula, enquanto era desenvolvida uma atividade em grupo. Esta instituição escolar atende senhores e senhoras, com idade avançada, que moram nas proximidades da Escola. Dos/as dezessete educandos/as que finalizaram o primeiro semestre de 2018 apenas quatorze estavam presentes no dia. Destes, $64,2 \%$ são do sexo feminino. São adultos/as e idosos/as entre 30 e 73 anos, oriundos/as, em sua maioria, da região nordeste do país (85, $71 \%$ ). 0 grupo se constitui de trabalhadores/as informais que trabalham como: doméstica, jardineiro, pedreiro, cuidadora de crianças, auxiliar de serviços gerais, salgadeira e dona de casa. Apenas uma senhora de 73 anos se declarou aposentada. Muitos/as são idosos/as que, mesmo tendo direito a uma aposentadoria, continuam trabalhando para garantir o sustento de suas famílias. São sujeitos persistentes que, ao almejarem uma melhoria na qualidade de vida, retomam os estudos e se apoiam em suas motivações pessoais para superar os obstáculos e o histórico de frustração que os/as acompanham.

Ao caracterizar os/as adultos/as da EJA, Oliveira (2001, p. 59) afirma que, de um modo geral, são migrantes de áreas rurais empobrecidas, filhos/as de trabalhadores rurais, sem qualificação, com baixo nível de escolaridade ou analfabetos/as; e, muitas das vezes, com "uma passagem curta e não sistêmica pela escola". Alguns/as se encontram na condição de subempregados/as e, quando voltam tardiamente à escola, sentem vergonha de sua condição educacional. Não obstante, por serem sujeitos excluídos da escola, são pessoas com experiências, conhecimentos acumulados e reflexões mais apuradas sobre si e do mundo; sujeitos com dificuldades e saberes diversos, que demandam um trabalho pedagógico diferenciado.

Desse modo, é necessário que a proposta curricular e o processo avaliativo considerem o legado da educação popular e a diversidade dos sujeitos; acolham os/as educandos/as; adequem-se aos tempos e espaços; proponham atividades e recursos didáticos diversos. Com esse intuito, buscase, por meio de um processo formativo (voltado para a aprendizagem dos/as educandos/as), superar práticas pedagógicas seletivas, excludentes, segregadoras e classificatórias que "impossibilitam que jovens, adultos e idosos sejam respeitados em seu direito a um percurso contínuo de aprendizagem, socialização e desenvolvimento humano" (FERNANDES; FREITAS, 2007, p.14).

Esse processo educativo, mais humano e humanizante, demanda uma prática avaliativa de concepção mais acolhedora, democrática e inclusiva, que incorpora a multiplicidade de olhares que compõe a dinâmica pedagógica, enriquecendo-a e estimulando a cooperação e a solidariedade. Essa prática avaliativa se consubstancia na avaliação formativa, descrita no Currículo em Movimento da Educação Básica - EJA (DISTRITO FEDERAL, 2014a); nas Diretrizes Operacionais da Educação de Jovens e Adultos (DISTRITO FEDERAL, 2014b); nas Diretrizes para a Avaliação Educacional: aprendizagem, institucional e em larga escala (DISTRITO FEDERAL, 2014c) e no Projeto Político Pedagógico da Escola pesquisada.

A avaliação formativa é uma avaliação mais abrangente, que envolve os/as educandos/as, dando-lhes condições de serem criativos/as e inovadores/as, de avaliarem seu processo e seus próprios trabalhos, possibilitando a incorporação de saberes às redes de conhecimentos preexistentes. Ela extrapola a lógica disciplinar, tão em voga nos currículos tradicionais. Essencialmente, porque possibilita que o conhecimento seja tecido em rede (coletivamente), favorecendo o diálogo entre os 
conteúdos programáticos, a realidade dos/as trabalhadores/as estudantes da EJA e a prática de sala de aula (OLIVEIRA, 2008, p.134). É um processo que favorece as aprendizagens e o sucesso escolar do/as educandos/as, e que será apresentado, com mais minucias, nas próximas sessões.

Contudo, é mister que o sistema educacional invista em formação específica de educadores e em políticas públicas que favoreçam o acesso e a permanência dos/as educandos/as, por meio de financiamento e políticas complementares de alimentação, transporte e material didático.

\section{APROXIMAÇÕES ENTRE O CURRÍCULO, A AVALIAÇÃO E OS DOCUMENTOS DA SEEDF}

Para atender a diversidade dos sujeitos que buscam a EJA como modalidade educativa, esta necessita ser diferenciada, com um currículo e uma avaliação coerentes com a realidade dos/as trabalhadores/as. Por isso, apresentam-se nesta seção os aspectos teóricos que evidenciam a relação existente entre esses temas.

O debate em torno dos temas do currículo e da avaliação tem recebido contribuições de estudiosos oriundos de realidades sociais e políticas distintas. Autores como Sacristán, Arroyo e Freitas, têm realizado discussões e questionamentos que contribuem não somente para a compreensão crítica da política educacional mais ampla, como também para a política cotidiana e local, consubstanciadas nas práticas escolares e na avaliação.

Ao refletir a contribuição destes autores, percebe-se o quanto o currículo é um "território de disputas". Segundo Arroyo (2011) quatro indicadores contribuem para que a realidade em torno do currículo tenha estas características. Para o autor, há uma disputa acirrada pelo conhecimento, pois se disputam interpretações epistemológicas que traduzem as contradições sociais, as quais fundamentam um novo projeto de sociedade mais digno e humano. Um segundo indicador para ele, é o fato do conhecimento incorporado no currículo não incorporar os saberes oriundos da "diversidade de coletivos sociais, étnicos, raciais, de gênero, campo e periferias" (ARROYO, 2011, p. 14). Um terceiro indicador é a relação que existe entre currículo e formação docente, uma vez que o professor é visto como o tradutor fiel do ordenamento curricular hegemônico. E por fim, Arroyo indica que as disputas travadas entre sociedade e Estado têm permitido o currículo se abrir para uma "riqueza de experiências sociais e de conhecimento e à diversidade de sujeitos políticos e culturais" (ARROYO, 2011, p. 17).

Em relação ao cotidiano escolar, esta disputa também ocorre nos diferentes embates entre o currículo prescrito e o real, espaço no qual os atores sociais constroem de forma criativa as propostas curriculares objetivadas em contextos mais amplos.

O currículo prescrito, segundo Sacristán (2000), é aquele formalizado e regulado por instâncias político-administrativas que estabelecem os conteúdos e as aprendizagens mínimos, fornecendo orientações metodológicas gerais que regulam a avaliação dos sistemas de ensino. Este nem sempre dialoga com a prática pedagógica, afastando-se assim do currículo real ou em ação - vivido no cotidiano da sala de aula. Segundo ele, o currículo em ação "é a última expressão do seu valor, pois 
enfim, é na prática que todo o projeto, toda idéia, toda intenção, se faz realidade [...] independentemente de declarações e propósitos de partida" (SACRISTÁN, 2000, p. 201).

O currículo em ação é orientado pelos pressupostos epistemológicos e filosóficos que embasam as escolhas de cada educador. Além disso, a avaliação atua como forma de modelar interna e externamente o processo de aprendizagem. Ou seja, a avaliação do currículo está vinculada aos mecanismos de informação gerados pelo sistema avaliativo. No caso da Educação de Jovens e Adultos do DF, há um conjunto de ordenamentos e orientações normativas que direcionam as disputas em torno daquilo que é considerado legítimo para ser incorporado como saber escolar. Neste processo, uma diversidade de atores se torna importante nesta definição, dentre eles, os movimentos sociais, universidade, educadores, governo, sindicatos, dentre outros; quais tiveram um peso significativo na elaboração do Currículo em movimento da EJA, aprovado pela Secretaria de Estado da Educação do DF (SEEDF), em 2014.

É importante mencionar que a construção desta proposta integrou um movimento mais amplo de discussão de toda a educação básica.

\begin{abstract}
A secretaria de Estado da Educação de Educação iniciou, em 2011, um movimento coletivo que envolveu professores(as), estudantes, coordenadores (as) pedagógicos (as), gestores do nível local, intermediário e central para discutir o currículo, apresentado no ano de 2010, de caráter experimental e propôs um nova estruturação teórica e metodológica, desse importante instrumento entendido como campo político-pedagógico construído nas relações entre os sujeitos, conhecimentos e realidades (DISTRITO FEDERAL, 2014a, p. 17).
\end{abstract}

No tocante a EJA, houve o reconhecimento de que somente a alteração curricular era insuficiente para a melhoria desta modalidade. Era necessário construir uma proposta curricular que dialogasse com as singularidades da pessoa jovem, adulta e idosa e que incorporasse as especificidades e diversidades presentes no universo desses sujeitos, considerando suas origens, culturas, saberes, conhecimentos e projetos de vida. Aderente a esse princípio, de acordo com a proposta curricular da SEEDF, a base comum do currículo da EJA pode ser trabalhada: de forma transversal e integrada aos três eixos norteadores - cultura, mundo do trabalho e tecnologia - que buscam dialogar com os saberes dos/as educandos/as e os conhecimentos propedêuticos; considerando os tempos e espaços, as diferenças geracionais, a diversidade cultural, social e econômica, bem como suas trajetórias e histórias de vida (DISTRITO FEDERAL, 2014a).

Desses três eixos, o mundo do trabalho suscita uma maior atenção, por estar imbricado na identidade de jovens, adultos/as e idosos/as oprimidos/as (Freire, 1987) e periféricos/as (ARROYO, 2007; 2017). Desta forma, não basta reconhecer as especificidades dos/as educandos/as da EJA, têmse que entendê-los/as, dentro de um ideário de educação popular - marcado por lutas, conquistas e superações - e como sujeitos histórico-culturais que se desenvolvem pela cultura e através da cultura. Assim, o currículo da EJA precisa dialogar com as diversidades (currículo multicultural) e contemplar os aspectos cognitivos, a subjetividade, o conhecimento social, político e cultural. Para isso, os conteúdos selecionados e a avaliação necessitam estar de acordo com a realidade dos sujeitos educativos, com o intuito de prepará-los para o exercício da cidadania, o mundo do trabalho e em estudos posteriores. 
Depreende-se desse contexto que a avaliação das aprendizagens, por ser um componente integrador da prática curricular, requer um viés formativo. Além de ser inclusiva e possibilitar a "democratização do conhecimento e a constituição de uma práxis educativa libertadora", ela precisa dialogar com a organização curricular e as especificidades do público alvo; propiciando a inclusão, a construção da autonomia, a mediação, a participação e a responsabilidade coletiva (FREITAS, 2008, p. 58).

Essencialmente porque a avaliação convencional contribuiu, por muito tempo, para os processos de exclusão na escola, por consagrar o privilégio cultural (BOURDIEU; CHAMPAGNE, 1998), por estar dissociada da vida real, por ter função meritocrática e excludente. Serviu como um instrumento de conformação da ordem, pois, segundo esses autores, somente as crianças das classes mais abastadas, com um maior capital cultural (conhecimento artístico e cultural transmitido pela família), obtinham êxito na escola, legitimando e produzindo a exclusão social das classes populares, que se mantinham em profissões menos nobres, numa espécie de "eliminação adiada". (FREITAS, 2002, p. 308).

O processo de democratização escolar, possibilitou o acesso de trabalhadores/as estudantes à escola, mas não garantiu a sua permanência, sobretudo, porque essa mudança no "metabolismo escolar", gerou uma transformação na forma de exclusão, incrementando as disparidades socioculturais (FREITAS, 2002, p. 309).

Os estudos de Freitas (2002) demonstram a centralidade da avaliação na organização do trabalho pedagógico, a qual tem uma intencionalidade sociopolítica - reproduzir os interesses da classe dominante -, e que por dissociar-se dos objetivos da aprendizagem, do desenvolvimento e do reconhecimento dos sujeitos culturais e impregnar-se de juízos de valores (avaliação informal, por parte do corpo docente, que pode sobredeterminar o sucesso ou fracasso escolar), acaba por contribuir para a exclusão social dos/as educandos/as (exclusão subjetiva).

Por esta razão, deve-se atentar para a relação entre o par dialético avaliação/objetivos, citada nos estudos de Freitas (1995), para que se tenha um processo mais coerente com a realidade dos/as educandos/as da EJA, haja vista a relevância desta relação para o processo de ensino e aprendizagem. A correlação entre o par dialético, referendado pelo autor, busca estabelecer a autonomia dos/as educandos/as, por meio de um trabalho reflexivo, voltado para as aprendizagens (perspectiva formativa) e não somente para os resultados (perspectiva somativa).

Lopes e Silva (2012) dividem a avaliação em: avaliação da aprendizagem; avaliação para a aprendizagem; e avaliação como aprendizagem. Para esses autores, a avaliação da aprendizagem "ocorre quando os educadores utilizam elementos da aprendizagem dos educandos para fazer julgamentos sobre o seu desempenho em relação aos objetivos de aprendizagem" (LOPES; SILVA, 2012, p. 5), a qual ocorre ao final do processo, sem a participação dos sujeitos educativos na planificação ou execução da mesma. Possui um caráter somativo, por descrever e quantificar o conhecimento, atitudes e competências.

A avaliação para a aprendizagem, segundo esses autores, é uma avaliação que ocorre com o objetivo de informar e promover as aprendizagens dos educandos, melhorando-as qualitativamente. $\mathrm{E}$ por fornecer dados sobre a aprendizagem, informar sobre o ensino, torna-se uma aliada da 
aprendizagem. Requer que o educador partilhe as metas de aprendizagem; ajude os educandos a compreender essas metas; forneça feedback construtivo; acredite na capacidade desses sujeitos educativos para aprimorar o progresso de suas aprendizagens (adquiridas dentro e fora do contexto escolar); assegure que os educandos aprendam estratégias de autoavaliação; e reconheça que a motivação e a autoestima são essenciais para a aprendizagem (LOPES; SILVA, 2012).

A avaliação como aprendizagem (autoavaliação) é um processo de reflexão, segundo o qual, o educando monitora o seu progresso e informa sobre seus futuros objetivos de aprendizagem, ajustando-a, a fim de reaprender, melhorando assim, o desempenho escolar. Uma atividade que requer do educando, a responsabilidade sobre o ato de aprender e sobre o processo avaliativo e envolve o processo de autoavaliação e a coavaliação. Na primeira forma de avaliação, o educando aprende sobre a aprendizagem, refletindo sobre o próprio trabalho ou atividades. Na segunda, aprende refletindo sobre as atividades e resultados de aprendizagem de seus colegas de classe. (LOPES; SILVA, 2012).

Não obstante, os avanços ocasionados pela Lei de Diretrizes e Bases da Educação de 1996 (LDB/96), pelas Diretrizes Operacionais da EJA e pelo Currículo em Movimento possibilitarem que o direito à uma educação de qualidade se formalizasse. Contudo, esta pesquisa problematiza as aproximações e discrepâncias entre o que está prescrito (nos documentos oficiais da SEEDF ${ }^{4}$ e no PPP da Escola pesquisada) e o que de fato é implementado no chão da Escola.

Para Oliveira (2007), os currículos da EJA precisam superar o formalismo e o cientificismo. Para isso, é mister a participação prévia de toda a comunidade escolar na seleção e organização dos conteúdos. A autora sugere a potencialização da aprendizagem por meio de redes de saberes e fazeres; o respeito à diversidade; a não fragmentação do conhecimento em matérias ou disciplinas, sem privilégios de uma sob a outra; a transversalidade entre as áreas do saber; o aprimoramento das competências argumentativas; e uma formação técnica e política, dentre outras.

$\mathrm{Na}$ concepção de Arroyo (2007, p. 46), as turmas devem ser agrupadas de acordo com as proximidades de trabalho, de "experiências sociais próximas de trabalho", para que se conceba uma estrutura curricular e um processo avaliativo que dialogue com as especificidades e saberes de suas vivências cotidianas.

\section{APROXIMAÇÕES ENTRE O CURRÍCULO, A AVALIAÇÃO E OS DOCUMENTOS DA SEEDF}

Os dados produzidos e discutidos neste artigo fazem parte de uma proposta interventiva de pesquisa-ação desenvolvida em uma Escola pública do Paranoá-DF. Desde agosto de 2017, vem sendo desenvolvido trabalho colaborativo com o grupo de educadores a fim de contribuir para a transformação e superação das dificuldades de aprendizagem de adultos/as e idosos/as, num processo de ação-reflexão-ação. Contribuição que Barbier (1997, p 101) denomina de implicação do pesquisador, que se traduz pelo engajamento pessoal e coletivo do pesquisador, em prol de um

\footnotetext{
${ }^{4}$ Currículo em movimento da educação básica - EJA (DISTRITO FEDERAL, 2014a), Diretrizes Operacionais da EJA (DISTRITO FEDERAL, 2014b), e Diretrizes de Avaliação Educacional (DISTRITO FEDERAL, 2014c).
} 
"projeto sociopolítico em ato". No caso do GENPEX, esta ação está atrelada à parceria histórica entre a Universidade de Brasília (UnB) e o Movimento Popular do Paranoá (CEDEP) há mais de 32 anos.

O trabalho de pesquisa-ação ocorre no laboratório de informática, no período noturno de segunda a quinta-feira, no horário das 19:20 às 21:20 e envolve as quatro etapas do primeiro segmento da EJA. A cada semestre, o número de educandos/as que participa das atividades varia. No ano de 2015, participaram cerca de 100 educandos/as. Destes, 49\% possuíam faixa etária superior a 51 anos, $3 \%$ abaixo de $30,20 \%$ com 31 a 40 anos, 10\% entre 40 a 50 anos, e $18 \%$ não declararam (SOBRAL e REIS, 2017).

As atividades realizadas junto aos/as educandos/as buscam valorizar as histórias de vidas e estimular as produções textuais que abordem aspectos relacionados ao contexto no qual os educandos vivem/trabalham/sonham e estudam. Tanto o momento da sala de aula como o do laboratório de informática é planejado, coordenado e direcionado por equipe da Universidade de Brasília, com a participação de estudantes, graduandos, mestrandos e doutorandos do curso de Pedagogia, que fazem parte do GENPEX.

Em relação aos dados produzidos para esta pesquisa, durante o segundo semestre de 2017 , acompanhamos o trabalho do GENPEX com os/as educandos/as no laboratório de informática, uma vez por semana, e tivemos participação nas reuniões semanais deste grupo. Após a avaliação realizada pelo grupo acerca do trabalho desenvolvido durante aquele semestre, novos percursos foram traçados, a fim de dinamizar o processo de alfabetização e promover maior autonomia e criticidade nos sujeitos educativos da Escola pesquisada. Assim, buscou-se acompanhar, durante o primeiro semestre de 2018, a alfabetização dos/as educandos/as da primeira etapa, duas vezes por semana, auxiliando os dois professores da turma - uma de português e um de matemática - em sala de aula, com as atividades criadas por eles ou intervindo com vivências educativas diversas. Esta situação, acordada com os educadores no início do semestre, está registrada no diário de itinerância da pesquisadora - instrumento do qual foram retiradas as informações da observação prática, que propiciaram o diálogo entre o currículo prescrito e o vivido, apresentadas aqui nesta seção.

A Educação de Jovens e Adultos na Escola pesquisada é ofertada no período noturno, desde 2015. Segundo o PPP da Escola, a unidade escolar orienta-se pelos princípios do Currículo em Movimento das Escolas Públicas do Distrito Federal - EJA (2014) e pelo Projeto Político Pedagógico Professor Carlos Motta (2012), cujas diretrizes dialogam com uma óptica de educação ampliada, reconhecendo a educação como um "direito universal de aprender ao longo da vida" (DISTRITO FEDERAL, 2012, p. 83-84), capaz de transformar jovens e adultos/as em cidadãos/ãs autônomos/as, críticos/as e ativos/as socialmente. A proposta curricular baseia-se nos três eixos integradores do currículo em movimento e trabalha os eixos transversais de forma interdisciplinar, respeitando as necessidades e diferenças individuais dos sujeitos.

Entretanto, percebe-se na práxis pedagógica realizada na primeira etapa, do primeiro seguimento, aproximações e distanciamentos das teorias do currículo e da avaliação na EJA, com o próprio PPP da Escola e, consequentemente, com os documentos oficiais da SEEDF. Este fato suscita reflexões que sugerem que a Escola encontra-se num processo de construção e adaptação curricular. Assim, ressalta-se como aproximações do currículo prescrito ao vivido: o acolhimento; o respeito aos 
espaços e tempos dos/a educandos/as trabalhadores/as; passeios diversos - proporcionados tanto pelo GENPEX quanto pela Escola - que diversificam o contato dos sujeitos educativos com outras manifestações culturais; e o dessilenciamento dos/as adultos/as e idosos/as, que ao longo das atividades desenvolvidas pelo GENPEX, discutem temas relevantes do dia a dia e desenvolvem textos coletivos, externalizando o que pensam, como se sentem e como se veem.

Embora os professores não tenham dificuldade para se comunicar com os/as educandos/as, evitem a infantilização e não se utilizem do dever de casa para promover a fixação do conteúdo, percebe-se que a proposta curricular incorpora de modo incipiente a avaliação como forma de desenvolver a autorreflexão e o automonitoramento. Segundo Documento das Diretrizes Educacionais do Distrito Federal (2014) a avaliação deve estar voltada para as aprendizagens - priorizando aspectos formativos - num processo contínuo e com procedimentos metodológicos diversos, os quais são descritos nas Diretrizes de Avaliação Educacional (2014). De acordo com tais documentos estes instrumentos são os seguintes: avaliação por pares, portfólio/EaD webfólio ou portfólio virtual, registros reflexivos, autoavaliação, seminários, pesquisas e trabalhos em grupo, testes e provas - até $50 \%$ da nota (numa perspectiva formativa).

Um dos educadores investigados ponderou que, a avaliação das aprendizagens "é um recurso docente que promove a aprendizagem autônoma do educando. Os resultados da avaliação têm que servir aos alunos para controlar melhor seus progressos. Verificar se os resultados foram alcançados". Em termos de definição, percebe-se que a concepção de avaliação docente está centrada no eixo da aprendizagem e na promoção do desenvolvimento desses sujeitos trabalhadores estudantes. Esse saber da ação demostrado pelo docente é condizente tanto com os documentos oficiais da SEEDF, quanto com o PPP da Escola.

O PPP da Escola assegura a centralidade na aprendizagem, ao afirmar que a avaliação será formativa e global, fundamentada nos processos de aprendizagem, em seus aspectos cognitivos, afetivos e relacionais e nas aprendizagens significativas e funcionais. Ao afirmar que a avaliação é um recurso para "verificar se os objetivos foram alcançados", o educador prioriza os objetivos da aprendizagem, o que decorre, na visão de Freitas (2005; 2014), do fato da prática do educador muitas vezes não se orientar por objetivos instituídos (pelo par dialético objetivo/avaliação). O que pode resultar numa prática avaliativa inconsistente com o tipo de avaliação apregoada nos documentos oficiais da SEEDF, cuja finalidade é a promoção das aprendizagens e, não, averiguar se os resultados foram atingidos.

Conforme o PPP da Escola, os instrumentos avaliativos utilizados são os seguintes: observações; relatórios descritivos, provas (escritas, oral, com/sem consulta, em grupo, individual, dissertativa, objetiva etc.); trabalhos (pesquisa, pesquisa de campo, elaboração de materiais didáticos, seminários, etc.); autoavaliação; participação nas aulas; projetos, dentre outros.

De acordo com Freitas (2008), a avaliação de caráter emancipatório deve englobar também a concepção de erro construtivo e o conselho de classe participativo. No entanto, observamos que esta prática ocorre parcialmente na Escola, pois os relatórios são feitos e não é enfatizado o erro de maneira construtiva. Além disso, os instrumentos não são diversificados, a autoavaliação e a participação dos/as educandos/as no conselho de classe não são práticas educativas adotadas. 
Segundo os próprios educadores, os/as educandos/as são avaliados por meio da participação, de atividades em grupo, de trabalhos feitos em sala e pela avaliação da leitura. O peso maior da análise do desempenho reside, entretanto, na prova escrita. Esta situação evidencia uma prática avaliativa mista, em que os aspectos formativos ainda não são implementados em sua plenitude, privilegiando mais o resultado da aprendizagem do que o processo em si.

Os/as educandos/as são informados/as sobre o resultado do seu progresso por meio do feedback fornecido pelos professores, após a realização das provas, e pelo Registro Avaliativo (RAv). Informação que se encontra no PPP da Escola, nas Diretrizes Operacionais da EJA (2014) e nas Diretrizes da Avaliação Educacional (2014). Segundo as observações de sala de aula e a fala dos professores no dia da prova escrita, o RAv é preenchido a partir dos resultados das avaliações e entregue aos/as educandos/as no último dia de aula, sem nenhuma discussão prévia sobre o seu desempenho. Esta circunstância ratifica a opinião de Corazza (2001) sobre os pareceres descritivos produzidos pelos professores, acerca do desempenho dos/as educandos/as, considerados como um instrumento à parte daqueles utilizados ao longo do processo avaliativo, quando ele próprio deveria ser utilizado com tal propósito.

Afora esses aspectos, foram observados no trabalho com os professores que, o eixo mundo do trabalho da proposta curricular do DF não dialoga com a prática pedagógica, pois os conhecimentos prévios e a história de vida são considerados parcialmente, por não ocorrer discussão com os/as educandos/as sobre o que eles pensam, sentem ou gostariam de aprender. Não há uma educação política, nos moldes de uma pedagogia do oprimido, como salienta Paulo Freire (1987), e tão pouco uma pedagogia para os passageiros periféricos, de itinerários desumanos, como argumenta Arroyo (2017) - já que o problema para este autor não é o letramento e sim a vida desumana que vivem os/as adultos/as e os/as jovens da EJA.

Ao longo do período em que a pesquisadora esteve em sala de aula, não foi possível averiguar o trabalho interdisciplinar dos conteúdos de ciências da natureza e ciências humanas com os de português e matemática. Não obstante, os exercícios de português e matemática ocorressem numa mesma aula, pareciam sem conexão uns com os outros. Percebe-se que ocorre uma seleção mínima de conteúdos que não chega a abranger os objetivos gerais e específicos do Currículo em Movimento. Este fato está em desacordo com a ideia de formação integral e cidadã, defendida pelos documentos oficiais da SEEDF e os teóricos aqui mencionados.

O currículo em movimento (2014) assegura, como um objetivo geral da língua portuguesa, a necessidade de se conhecer, ler e produzir diferentes modalidades de texto de forma autônoma. Tais situações têm ocorrido com mais freqüência nas intervenções realizadas na Escola por meio do GENPEX, que trabalha com a leitura deleite, textos de diferentes gêneros literários, lidos e discutidos com os/as educandos/as, e com a produção de textos coletivos, produzidos a partir da discussão de algum tema de cunho político e social.

O GENPEX, ao trabalhar com "o acolhimento (amorosidade), a discussão de situaçõesproblema-desafios e o uso de textos coletivos" (Vieira, 2017, p.7), dialoga com um currículo multicultural, por abordar os eixos integradores tanto nas atividades realizadas no laboratório de informática quanto em sala de aula, buscando atender às demandas coletivas dos/as educandos/as, 
integrando novos conhecimentos ao "saber de experiência feito" (saber do senso comum), dessilenciando-os/as e contribuindo, assim, para que se sintam sujeitos de sua própria história. Diante desse fato, percebe-se que a parceria do GENPEX com a Escola pesquisada tem sido profícua, pois possibilita a execução de projetos criativos e inovadores, capazes de atender à demanda da comunidade escolar.

Por meio das observações, das intervenções e de conversas informais com os/as educandos/as e educadores da primeira etapa, registradas no diário de itinerância, foi possível constatar o modo como a Escola tem atendido às necessidades desses sujeitos trabalhadores, oprimidos e periféricos e sua relação com a ausência de uma formação de professores específica para atuarem na EJA. Não obstante, percebem-se mudanças gradativas no trabalho pedagógico da Escola, tendo como horizonte o que está estabelecido no PPP - principalmente por se propor a trabalhar numa perspectiva histórica cultural, dentro de um viés transformador - e nos documentos da SEEDF.

\section{ALGUMAS CONSIDERAÇÕES}

Os estudos sobre o currículo e a avaliação da EJA, apresentados pelos autores, utilizados no corpo deste artigo, demonstram que desde os anos 1960, início da atuação de Paulo Freire em educação de adultos, já se falava em uma proposta curricular que dialogasse com o perfil dos/as educandos/as, valorizando seu saber de experiência feito. Essas ideias são abarcadas também pelos documentos institucionais da SEEDF e pelo PPP da Escola pesquisada, que trazem uma concepção histórico-cultural dos sujeitos da EJA e focam nos três eixos norteadores (cultura, mundo do trabalho e tecnologia), dialogando com a diversidade desse público, assegurando-Ihes uma educação integral e cidadã.

Contudo, no chão da Escola, percebe-se poucos avanços na ruptura de concepções e práticas. Logo, a EJA continua sendo relegada a políticas assistencialistas, compensatórias de governo, as quais não sustentam o aporte teórico desta modalidade e mantém o descompasso entre o prescrito e o vivido. Especialmente na prática pedagógica, em que o currículo e avaliação continuam não dialogando com esses sujeitos educativos, desvinculados do conhecimento popular, que não se alinha com os saberes fragmentados, impostos pela lógica neoliberal, de preparação para o mercado de trabalho, voltada para um emprego "inseguro", para um futuro incerto que, de fato, não os contemplam.

A avaliação formativa, ainda, não consegue ser praticada em sua totalidade, seja por desconhecimento, falta de formação específica, ou por falta de vontade política e/ou pedagógica. Logo, faz-se necessário: ajustar a avaliação aos objetivos da modalidade, para que o trabalho pedagógico se torne mais coerente e voltado para o desenvolvimento das aprendizagens; repensar o currículo e avaliação na formação docente; as questões relativas à administração e à gestão escolar; e as políticas públicas, que favorecem o acesso e a permanência na EJA.

Além desses aspectos, a pesquisa desvela a importância da questão afetiva e o vínculo existente entre os educadores, o grupo do GENPEX e a coordenação para a permanência dos/as educandos/as, que se se sentem gratos/as e satisfeitos/as com os resultados adquiridos ao longo do 
semestre. Esse acolhimento e essa amorosidade os/as motivam e fazem com que muitos/as desses/as trabalhadores/as oprimidos/as, superem os percalços dessa caminhada incerta, marcada por incompreensões e injustiças e ressignifiquem seu viver.

Contrariamente às pesquisas de natureza positivista que se restringem a descrever, explicar e prever os fenômenos, de maneira neutra e objetiva, a pesquisa-ação situa-se na perspectiva da mudança social. Tem a marca de um compromisso com a interpretação, mas, sobretudo, visa transformar a realidade problematizada. Dessa forma, o trabalho de pesquisa-ação desenvolvido na Escola pesquisada, fruto da parceria entre a Universidade de Brasília e o Movimento Popular do Paranoá, possibilita a ruptura de concepções e práticas assistencialistas e compensatórias na EJA, à medida em que diversifica as atividades pedagógicas e dá voz aos sujeitos educativos. E por intermédio da interação dos pesquisadores coletivos com os sujeitos da pesquisa, promovem-se mudanças tanto no contexto escolar quanto no contexto comunitário.

Essencialmente porque a pesquisa-ação emerge como problematização da realidade ou na identificação de problemas sociais que atingem determinados grupos sociais. No entanto, para além da mera identificação, o grupo se reúne para discutir as questões geradoras ou situações-desafios que Ihes afligem e a melhor forma de superá-las. Tais situações-problemas são discutidas e analisadas entre estudantes da pedagogia, alfabetizadores e educandos/as da Educação de Jovens e Adultos. Por meio dessa vivência, o grupo intenta romper a clássica dicotomia entre pesquisa e ação, no qual percebe ser possível aprender e conhecer enquanto transforma, e, transformar enquanto se conhece e aprende. 


\section{REFERÊNCIAS}

ARROYO, M.G. Balanço da EJA: o que mudou nos modos de vida dos jovens-adultos populares? Revista de Educação de Jovens e Adultos, v. 1, n. 0, p. 1-108, ago. 2007. Disponível em: http://mariaellytcc.pbworks.com/f/REVEJ@_0_MiguelArroyo.pdf. Acesso em 25 de maio de 2018.

2. Petrópolis, RJ: Vozes, 2017.

4. BARBIER, R. A pesquisa-ação. Brasília: Plano Editora, 2002. 159 p. - (Série Pesquisa em Educação, v.3).

5. BRANDÃO, C. A educação popular antes e agora. In Maria Margarida Machado (Org). Formação de educadores de jovens e adultos. Brasília: Secad/MEC, UNESCO, 2008.

6. BRASIL. Lei n.9394, de 20 de dezembro de 1996. Estabelece as diretrizes e bases da educação nacional. Diário Oficial da união, 23 dez. Brasília, 1996.

7. BOURDIEU, P.; CHAMPAGNE, P. Os excluídos do interior. In: NOGUEIRA, M. A.; Alegre: Artmed, 2000.

8. CORAZZA, S. O que quer um currículo? Pesquisas pós-críticas em educação. Petrópolis, RJ: Editora Vozes, 2001.

9. DISTRITO FEDERAL. Secretaria de Estado de Educação. Currículo em movimento da Educação Básica. Educação de Jovens e Adultos. 2014a. Disponível em: http://www.se.df.gov.br/component/content/article/282-midias/443-curriculoemmovimento.html. Acesso em 12/11/2017. . Secretaria de Estado de Educação. Diretrizes operacionais da educação de jovens e adultos 2014/2017. Brasília, 2014b.

. Secretaria de Estado de Educação do Distrito Federal. Diretrizes de avaliação educacional, aprendizagem, institucional e em larga escala, 2014-2016. Subsecretaria de Educação Básica. Brasília, 2014c. 
13. FERNANDES, C. O.; FREITAS, L C. Indagações sobre currículo: currículo e avaliação. Organização do documento: JeaneteBeauchamp, Sandra Denise Pagel, Aricélia Ribeiro do Nascimento. Brasília: Ministério da Educação, Secretaria de Educação Básica, 2007.

14. FREIRE, P. Pedagogia do oprimido. 17. Ed. Rio de Janeiro: Paz e Terra, 1987.

15. FREITAS, A.L S. Fundamentos, dilemas e desafios da avaliação na organização curricular por ciclo de formação. In: ESTEBAN, M. T. (Org.). Escola, Currículo e Avaliação - Série Cultura, Memória e Currículo; v. 5. São Paulo: Cortez, 2008.

16. FREITAS, L. C. A internalização da exclusão. Educação \& Sociedade. Campinas, v. 23, n. 80, set./2002, p. 301-327. Crítica da organização do trabalho pedagógico e da didática. Campinas, SP: Papirus, 1995.

LOPES, J.; SILVA, H. S. 50 Técnicas de Avaliação Formativa. Lisboa: Lidel, 2012.

OLIVEIRA, I. B. Reflexões acerca da organização curricular e das práticas pedagógicas na EJA. Educar, Curitiba, n. 29, p. 83-100. Editora UFPR, 2007. Pensando o currículo na educação de jovens e adultos. In:Oliveira, Inês. Educação de jovens e adultos. Rio de Janeiro, DP\&A, 2004.

21. SACRISTÁN, J. G. O Currículo: uma reflexão sobre a prática. 3.ed. - Porto Alegre: Artmed, 2000. Cap. 4 e 5.

22. SANTOS, J. S.; PEREIRA, M. V. Educação de Jovens e Adultos: um currículo que demanda mais atenção. Disponível em: http://educere.bruc.com.br/arquivo/pdf2017/24764_13108.pdf. Acesso em: 05/06/2018.

23. SOBRAL, J. B. L.; REIS, R. H. Ação-reflexão-ação em uma escola pública do Paranoá-Distrito Federal: uma perspectiva de educação popular na educação de jovens e adultos. Revista Comcenso. Vol, 4, n. 2, maio 2017.

24. SOARES, L.; SOARES, R. O reconhecimento das especificidades da Educação de Jovens e Adultos: constituição e organização de propostas de EJA. Revista Arquivos Analíticos de Políticas Educativas, vol. 22, n. 66, jun/2014, pp. 1-22.

25. THIOLLENT, M. Metodologia da Pesquisa-ação. São Paulo: Editora: Cortez, 1997. 
26. VIEIRA, M. C. Comunidades de práticas como espaços de formação inicial na educação de jovens e adultos: uma análise a partir da experiência do Genpex /UnB. 38 Reunião Nacional da ANPED. UFMA - São Luís/MA, 2017.

27. _. Memorias-testemunho de educadores: contribuições da educação popular a educação de jovens e adultos. Curitiba:CRV, 2016.

28. VILAR, J. C.; ANJOS, I. R. S. Currículo e práticas pedagógicas na educação de jovens e adultos. Espaço do Currículo, v.7, n.1, p.86-96, janeiro a abril de 2014. Disponível em: http://periodicos.ufpb.br/ojs2/index.php/rec. Acesso em: 12/04/2018.

\section{Reijane da Silva Lopes}

Psicóloga, pedagoga e psicopedagoga. Mestre em Educação pela Universidade de Brasília - UnB.

\section{Maria Clarisse vieira}

Professora associada da Faculdade de Educação e do Programa de Pós-graduação em Educação da Universidade de Brasília. É Pedagoga com mestrado em Educação pela Universidade Federal de Uberlândia e doutorado em Educação pela Universidade Federal de Minas Gerais.

\section{Como citar este documento}

LOPES, Reijane da Silva; VIEIRA, Maria clarisse. Aproximações entre avaliação e currículo na educação de jovens, adultos e idosos. Reflexão e Ação, Santa Cruz do Sul, v. 28, n. 1, jan. 2020. ISSN 1982-9949. Disponível em: <https://online.unisc.br/seer/index.php/reflex/article/view/13586>. Acesso em: . doi:https://doi.org/10.17058/rea.v28i1.13586. 